\title{
A SOLIDARIEDADE EM AÇÕES PEDAGÓGICAS NA MODALIDADE EAD
}

\author{
Regina Trilho Otero Xavier \\ Universidade Católica de Pelotas (UCPel) \\ E-mail: trilhote@ucpel.tche.br \\ Sérgio R. K. Franco \\ Universidade Federal do Rio Grande do Sul (UFRGS) \\ E-mail: sergio.franco@ufrgs.br \\ Maria Isabel da Cunha \\ Universidade do Vale do Rio dos Sinos (UNISINOS) \\ E-mail: cunhami@uol.com.br
}

\begin{abstract}
RESUMO
O presente artigo versa sobre o tema conhecimento-solidariedade em EAD. O objetivo principal do estudo é contribuir para a implementação de ações pedagógicas em EAD na perspectiva do conhecimento-solidariedade. A partir, principalmente, dos referenciais de Boaventura Santos, Jean Piaget e Yves de La Taille procura-se compreender o que vem a ser o conhecimentosolidariedade, bem como os valores e saberes que favorecem a ocorrência de ações pedagógicas de professores e alunos em EAD nessa perspectiva.
\end{abstract}

Palavras-chave: EAD, solidariedade, saberes docentes.

\begin{abstract}
The present article turns on the subject knowledge-solidarity in Distance Education. The main objective of the study is to contribute for the implementation of pedagogical actions in Distance Education in the perspective of knowledge-solidarity. Using mainly the referenciais of Boaventura Santos, Jean Piaget and Yves de La Taille it is looked to understand what it comes to be knowledge-solidarity, as well as the values and knowledges that favor the occurrence of pedagogical actions of professors and pupils in Distance Education in this perspective.
\end{abstract}

Key words: Distance Education; solidarity ;teaching knowledge. 


\section{Introdução}

A Educação, tendo grande responsabilidade na formação das sociedades, necessita buscar constantemente no passado a razão dos acontecimentos do presente, como forma de iluminar ações futuras. Pensando nessa linha, relaciona-se, a seguir, a forma de pensar o conhecimento com o comportamento humano, em especial com as ações educativas, e procura-se buscar a gênese de uma forma de conhecimento que possa resultar em transformações positivas para a humanidade: o conhecimentosolidariedade. Sobretudo, procura-se explicitar os valores que estão na base das ações.

A obra de Boaventura Santos busca esclarecer os valores que presidem os modos de fazer ciência. Neste sentido, o autor concebe a existência de duas concepções de conhecimento, de educação e de sociedade, as quais denominou paradigma dominante da ciência moderna e paradigma emergente ou paradigma da solidariedade.

De acordo com Santos (1987), em seu surgimento, o paradigma dominante da ciência moderna precisou combater o paradigma, então vigente, que se fundamentava na religião e no senso comum. Para vencer, baseou-se - havendo, em certos casos, um certo excesso - na neutralidade, na objetividade e numa concepção de universo como um sistema mecânico, composto de unidades materiais elementares, onde o ser humano é visto como totalmente separado da natureza e a natureza é vista como estando a serviço do humanidade.

A visão de mundo e de ser humano, resultante desse paradigma, influenciou, não só as ciências exatas, como as ciências humanas. A Educação atual ainda tem forte influência do paradigma dominante, o que afeta a qualidade das sociedades, uma vez que, ao moldar a Educação, esse paradigma moldou também o indivíduo. Várias potencialidades humanas tiveram de ser contidas, como a sensibilidade, a emoção e a intuição, por serem incompatíveis com o sistema de ensino vigente. As características pessoais dos aprendentes tiveram que ser subjugadas muitas vezes, encontrando poucos momentos para manifestarem-se. O mundo, na época do surgimento e fortalecimento desse paradigma, era de padronizações, de ordens e de se fazer as "coisas" como sempre foram feitas. Atualmente, uma conseqüência da influência desse paradigma, sentidas com muita clareza, referem-se ao individualismo exagerado.

Nas escolas e universidades, a forte influência do cientificismo pode ser sentida tanto na lógica da construção dos currículos, quanto na prática docente. A qualidade das relações interindividuais nas salas de aula costuma sofrer influência dos fundamentos de individualismo e egocentrismo característicos do paradigma dominante.

Especialmente dois fatores, a Educação baseada no paradigma da ciência moderna e as mudanças extremamente velozes, levaram-nos a viver num mundo de superficialidades, efemeridades, virtualizações. Porém, ao mesmo tempo, um mundo que distancia o ser humano de si mesmo, uma vez que se acostumou a isso por não encontrar espaços que estimulem - muitas vezes, sequer permitam - a sua expressão.

De acordo com Santos (2002), os paradigmas nascem, desenvolvem-se e morrem. Assim, a partir do momento em que as grandes promessas de progresso para a humanidade não ocorreram e graves devastações do meio-ambiente passaram a ocorrer com maior freqüência e amplitude, não foi mais possível deixar de perceber o nascimento de um outro paradigma: o paradigma emergente, também denominado paradigma da solidariedade. 
Esse novo paradigma baseia-se em uma nova maneira de fazer ciência, uma ciência como um ato humano, preocupado em buscar para a humanidade, como um todo, "um conhecimento prudente para uma vida decente" (Santos, 1987).

No presente artigo, considera-se que toda a formação, toda a vida do professor são, de alguma forma, refletidas na sua ação docente. Assim, é importante reconhecer a influência de determinados paradigmas nas ações desenvolvidas pelos professores, como, também, reconhecer que uma concepção de conhecimento e uma teoria moral subjazem às ações docentes.

\section{Saberes Docentes na perspectiva do conhecimento solidariedade}

A ação docente na perspectiva do conhecimento-solidariedade encontra algumas barreiras a transpor. Muitas delas são decorrentes do paradigma da ciência moderna que influenciou fortemente os modos de pensar e agir. Nesse sentido, o entendimento e a conscientização dessa influência se constituem em pontos importantes para o professor que deseja direcionar suas ações na perspectiva da solidariedade. Conhecer as características e as razões de ser dos paradigmas dominante e emergente pode constituir-se em possibilidade de aproximação para a adoção de um caminho mais solidário. Assim sendo, entendendo que EAD é, sobretudo, Educação, a seguir serão apresentados os saberes docentes tanto da educação presencial, quanto da $\mathrm{EAD}$, que favorecem ações pedagógicas na perspectiva do conhecimento-solidariedade.

Moraes (1996) utiliza o termo paradigma emergente para caracterizar uma nova forma de pensar a Educação mais adequada aos dias de hoje e que objetiva a formação de seres intelectual e humanamente competentes. De acordo com a autora o paradigma educacional emergente é: construtivista, interacionista, sócio-cultural e transcendente. Moraes (2004), ampliando seu posicionamento, denomina, ainda, de ecossistêmico o paradigma educacional necessário para acompanhar as características atuais de complexidade, desordem, indeterminância, intersubjetividade, dinâmica não-linear e autoorganizaçao. O paradigma ecossitêmico traz consigo um sentimento de pertencimento mútuo à terra e ao cosmo, uma consciência de destino comum e de compromisso fundamental com a vida. Além disso, esse paradigma é, também, acompanhado de um pensamento ecológico que é aberto, relacional, sempre em movimento.

\section{A concepção de aprendizagem construtivista}

Para Becker (2001), construtivismo não é apenas um modo de ser do conhecimento, é, também, um modo de ver o universo, a vida e o mundo das relações sociais. Construtivismo é uma teoria na qual o conhecimento é constituído na interação do indivíduo com o objeto de conhecimento, sendo que a qualidade dessa interação interfere substancialmente tanto no conhecimento construído pelo sujeito, quanto na subjetividade e no comportamento adotado pelo sujeito.

De acordo com Piaget (1995), no desenvolvimento intelectual tudo é criação. Todo o desenvolvimento da inteligência é caracterizado pelo aparecimento de estruturas totalmente novas, numa criação contínua a partir da atividade do sujeito sobre o meio. $\mathrm{O}$ mundo externo é incorporado às estruturas do sujeito a partir de atos de assimilação num sentido realmente biológico. Fazendo uso dos processos de generalização, equilibração e da abstração reflexionante, o que começa com uma ação do sujeito, vai resultando numa recriação do mundo - do seu mundo - e numa criação de si mesmo. 
O conhecimento ocorre, então, num processo contínuo de criação de novidades que se inicia com a função de assimilação desde o período sensório-motor. Já nesse período existe, também, o processo de abstração reflexionante o qual teve início nos desequilíbrios, reequilibrações, generalizações e novas construções. São exatamente essas novas construções que ocorrem a partir de elementos que são retirados do sistema anterior que caracterizam a abstração reflexionante.

\section{A pedagogia relacional}

O professor que concebe o processo de aprendizagem de acordo com o construtivismo tenderá a agir de acordo com a pedagogia relacional (Becker, 2001). Alguns pressupostos observados por este professor dizem respeito à valorização que dá ao seu aluno, considerando-o sempre com capacidade de aprender, e à valorização (mas não a supremacia) dos conteúdos como necessários para a construção de estruturas que apoiarão a assimilação de novos conteúdos e a construção de novas estruturas, em um processo sem fim.

O professor que atua de acordo com a pedagogia relacional inclina-se à criação de ambientes de aprendizagem que levem em conta características do construtivismo como, por exemplo, deixar o aluno assumir o controle de sua aprendizagem e escolher atividades que lhes sejam significativas. $\mathrm{O}$ fato de o aprendiz estar fazendo algo que parte de seus interesses e que é executado conforme seu estilo cognitivo, propicia o aparecimento de um sentimento de autoria que faz com que ele desenvolva um investimento afetivo com o que está aprendendo. Em geral, é este sentimento de estar trabalhando em algo que é seu - não a partir de uma ordem exterior - que faz com que a aprendizagem seja prazerosa para o educando, aumentando sua auto-estima e liberando mais energia para seguir adiante, em busca de novas superações.

Freire (1997) destaca alguns saberes que julga serem indispensáveis à prática educativa, tanto de educadores críticos e progressistas, quanto de educadores conservadores. $\mathrm{O}$ autor salienta que ensinar exige respeito aos saberes do educando, criticidade, corporeificação das palavras pelo exemplo, reflexão sobre a prática, respeito à autonomia do educando, alegria, curiosidade, humildade, comprometimento e querer bem aos educandos.

\section{Saberes éticos na perspectiva do conhecimento-solidariedade}

Não basta o desejo de ser solidário. Agir de acordo com o conhecimentosolidariedade exige competência cognitiva (saber ser solidário), competência afetiva (querer ser solidário) e, ainda, um contexto favorável (poder ser solidário). O saber ser solidário resulta em personalidade ética, quando os deveres éticos constituem-se em desejos que partem do próprio sujeito, representando, assim, seus valores fortes. $\mathrm{O}$ querer ser solidário envolve as capacidades de equacionamento moral e sensibilidade moral (La Taille, 2006), as quais permitem ao indivíduo perceber que existe uma questão moral envolvida em determinadas situações, o desejo de resolvê-las da melhor forma possível para os sujeitos envolvidos e o conhecimento de como equacionar estas situações da melhor forma possível. O poder ser solidário está diretamente vinculado aos limites individuais e relativos a contextos, os quais podem favorecer, dificultar ou, até mesmo, impedir a ação na perspectiva do conhecimento-solidariedade.

Considerando-se somente as questões éticas, que saberes docentes estão envolvidos quando o docente desejar agir na perspectiva do conhecimento- 
solidariedade? Ou ainda, que sentimentos e atitudes compõem o saber docente nessa perspectiva? Nesse momento, podemos partir de dois pontos básicos: a capacidade de descentração e o sentimento de respeito. Os estudos de Marques (2005) sobre egocentrismo e descentração na docência do ensino superior nos relatam que, em relação à descentração, existem três categorias de docentes. A primeira seria formada por docentes que não conseguem descentrar, considerando, substancialmente, a própria perspectiva em suas aulas. A segunda categoria seria formada pelos docentes que conseguem descentrar e desejam considerar a perspectiva dos alunos, mas não são capazes de coordenar a perspectiva própria com a dos alunos; pensam os alunos, porém a partir de si próprios. E a terceira categoria, formada pelos professores que conseguem se descentrar e conseguem coordenar a perspectiva própria com a dos alunos: são professores que estão, constantemente, tentando conhecer o pensamento do aluno, seus desejos, seus motivos de prazer.

Com relação ao respeito dirigido aos alunos, Marques (2005), ressalta que o professor da primeira categoria, ao não descentrar, também não está conhecendo o outro. Nesse caso, não há o respeito, já que o outro está sendo negado. Para os professores da segunda categoria, existe respeito aos alunos, porém é um respeito passivo, conforme Becker (2004), pois o outro é visto a partir de si próprio, de seus pontos de vista. Já os professores da terceira categoria pensam o aluno a partir do aluno e dirigem a ele um respeito ativo (Becker, 2004), caracterizando uma atitude de abertura ao outro, de escuta e de ação no sentido de promover uma aprendizagem consistente.

Além das questões de descentração e respeito ativo, sentimentos como empatia, auto-respeito, honra, vergonha, confiança, responsabilidade, culpa, obrigatoriedade, indignação, assim como necessidade de expansão de si mesmo, são essenciais à moralidade, compondo, assim, os saberes docentes na perspectiva do conhecimentosolidariedade.

La Taille (2006) prefere utilizar o termo simpatia, ao invés de empatia, para falar do tipo de sensibilidade pra com as outras pessoas que permite, a quem a sente, perceber o sentimento alheio e ser afetado por esse sentimento. No presente artigo será utilizado o termo empatia para designar essa sensibilidade. Empatia envolve conhecimento da existência do outro com alguém que têm valor, que é digno de confiança. Ser uma pessoa digna de confiança envolve considerar a moralidade das ações dessa pessoa. Uma das razões de ser digno da confiança de outras pessoas é ter integridade, isto é, ter coerência entra o que se diz e o que se faz. O sentimento de confiança nas figuras de autoridade é um forte componente do sentimento de obrigatoriedade para as pessoas que as cercam, funcionando como um exemplo a ser seguido. Além disso, a falta de confiança nas figuras de autoridade tem o efeito de abalar seu poder, de enfraquecê-las como autoridade perante os olhos alheios. Assim sendo, quando o sentimento de obrigatoriedade estiver ligado à necessidade de seguir determinados deveres porque esses são concebidos como expressão de seu próprio valor como pessoa, é porque a definição de vida boa para essa pessoa inclui capacidade de ver-se como pessoa de valor, capaz de afirmar-se dessa forma e de elevar-se, desenvolver-se.

O sujeito autônomo, embora possua preocupação em merecer a confiança dos outros, se tiver auto-respeito bastante forte, considerará que ser merecedor da própria confiança, isto é, ser um sujeito honrado é mais importante, ainda, do que merecer a confiança dos outros. A pessoa honrada procura sempre ser fiel a si mesma, a seus princípios e agir guiada por eles. Para esta pessoa, respeitar-se e agir com respeito pelos 
outros têm o mesmo significado. É o sentimento de auto-respeito que faz com que a pessoa sinta-se obrigada a constantemente agir de acordo com seus valores, uma vez que só assim conseguirá manter representações de si com valor positivo. Por estas razões, o auto-respeito constitui-se em motivação para o agir moral. O auto-respeito é um caso particular de auto-estima que ocorre quando "a valorização de si próprio incide sobre valores morais" (La Taille, 2006, p.55).

O sentimento de vergonha é responsável pelo auto-respeito, pela personalidade ética. Em geral, esse sentimento inclui "um certo desconforto decorrente da exposição pública” (La Taille, 2002, p.77), embora seja possível sentir vergonha sozinho.

O juízo negativo emitido por outra pessoa pode causar indignação quando a pessoa julgada negativamente considerar que um direito seu foi desrespeitado. A indignação pode também ocorrer quando direitos de outros tiverem sido desrespeitados, quando ocorrem atos que traduzem alguma forma de desrespeito.

Uma tendência dos seres humanos é a busca de representações de si como valor positivo. Esta necessidade de se ver com valores positivos nem sempre se encontra vinculada a valores éticos. Isto vai depender dos valores que o sujeito escolher para associar a sua imagem. Porém, todos procuram colocar-se como sujeito de direitos e procuram ser tão importantes quanto os demais. Essa reivindicação de atribuição de valor está fortemente vinculada à busca da auto-superação, representando uma busca constante pela expansão de si próprio.

O quadro a seguir, com a finalidade de fornecer uma visão conjunta, procura relacionar as dimensões do saber, querer e poder ser solidário com características dessas dimensões.

Quadro 1: Dimensões do saber ser, querer ser e poder ser solidário

\begin{tabular}{|c|c|c|}
\hline DIMENSÃO 1 & DIMENSÃO 2 & DIMENSÃO 3 \\
\hline \multirow[t]{15}{*}{ Saber ser } & Auto-conhecimento & Capacidade de buscar as razões de suas próprias ações \\
\hline & Descentração & Capacidade de considerar o pensamento do outro a partir do outro \\
\hline & Reciprocidade & Capacidade de valorizar ações de outro de forma idêntica à do autor da ação \\
\hline & $\begin{array}{l}\text { Tomada de } \\
\text { consciência }\end{array}$ & Consciência da própria subjetividade e de suas ações (morais, afetivas e intelectuais) \\
\hline & $\begin{array}{l}\text { Objetividade } \\
\text { Progressiva }\end{array}$ & Conhecimento, cada vez mais aproximado, do real \\
\hline & Criatividade & Capacidade de inovação, de produzir a partir de si mesmo \\
\hline & \multirow{5}{*}{$\begin{array}{l}\text { Equacionamento } \\
\text { Moral }\end{array}$} & Espírito de justiça \\
\hline & & Capacidade de destacar elementos morais, mesmo quando não estão claros \\
\hline & & Capacidade de pensar nos pressupostos dos elementos morais \\
\hline & & Capacidade de hierarquizar os elementos morais \\
\hline & & Capacidade de dar sustentação precisa a seus julgamentos \\
\hline & \multirow[t]{4}{*}{ Sensibilidade Moral } & Espírito de generosidade \\
\hline & & Capacidade de estar atento a singularidades, a contextos, a detalhes \\
\hline & & Vontade e capacidade de pensar \\
\hline & & Capacidade de ler nas entrelinhas, de interpretar sinais, de perceber a sensibilidade alheia \\
\hline \multirow[t]{4}{*}{ Querer ser } & Auto-respeito & Capacidade de associar representações de si aos seus valores morais \\
\hline & Respeito mútuo & Capacidade de respeitar o outro em suas diferenças e de vê-lo a partir dele mesmo \\
\hline & Empatia & Capacidade de colocar-se no lugar do outro e sentir suas emoções \\
\hline & Indignação & $\begin{array}{l}\text { Capacidade de perceber e não aceitar formas de desrespeito ou/e desvalorização para } \\
\text { consigo ou para com o outro }\end{array}$ \\
\hline
\end{tabular}




\begin{tabular}{|c|c|c|}
\hline & Confiança & Capacidade de coerência entre o que diz e faz e capacidade de acreditar no outro \\
\hline & Obrigatoriedade & $\begin{array}{l}\text { Capacidade de sentir-se internamente obrigado ao desempenho de atitudes éticas, } \\
\text { fundamentadas por princípios próprios }\end{array}$ \\
\hline & Responsabilidade & $\begin{array}{l}\text { Capacidade de sentir-se responsável por suas ações com consciência das repercussões } \\
\text { que elas podem ter no presente e no futuro, tanto para si, como para sua comunidade e } \\
\text { planeta }\end{array}$ \\
\hline & Honra & Capacidade de ser fiel a si mesmo, a seus princípios e de agir guiado por eles \\
\hline & $\begin{array}{l}\text { Incentivo a relações } \\
\text { de cooperação }\end{array}$ & $\begin{array}{l}\text { Capacidade de demonstrar e incentivar a importância da cooperação para o } \\
\text { desenvolvimento de todos }\end{array}$ \\
\hline Poder ser & Ambiente cooperativo & $\begin{array}{l}\text { Capacidade de incentivar a criação de ambiente cooperativo com princípios de } \\
\text { liberdade, respeito mútuo e reciprocidade }\end{array}$ \\
\hline
\end{tabular}

\section{Os saberes técnicos e de gestão em EAD}

Os saberes técnicos em EAD referem-se aos conhecimentos sobre o uso das Tecnologias da Informação e da Comunicação (TIC)e dos Ambientes Virtuais de Aprendizagem (AVA) que os docentes terão a sua disposição. Em geral, os recursos mais utilizados dizem respeito a processadores de texto, softwares de apresentação, planilhas eletrônicas e uso de vídeos. Os maiores problemas com relação ao domínio destes recursos costumam ocorrer pelo medo por parte dos professores de errarem ao tentar usá-los, à falta de paciência para aprender, ao esquecimento dos passos necessários para atingir o fim desejado, ao pouco tempo que têm para aprender ou, ainda, à falta de equipamentos, softwares e/ou pessoal qualificado para ensinar os professores a usá-los.

Outro ponto importante é conhecer as características do aluno virtual. Em geral, para que este aluno tenha seu desempenho favorecido, são desejáveis características como: autonomia intelectual e moral e disciplina. Assim, conseguirá impor-se horários de estudo e irá produzir os próprios trabalhos por julgar que é melhor para si próprio. Um aspecto que não pode ser desconsiderado é o alto índice de evasão existente em EAD. Para amenizar esse aspecto, a ação cuidadosa e constante do professor, pode contar com um aliado poderoso: a relação aluno-aluno.

Um aspecto da EAD característico da EAD é a possibilidade de muitas trocas, de muita comunicação entre os participantes, em função dos recursos que podem ser disponibilizados. Tal fato permite que o professor incentive as trocas aluno-aluno. São essas trocas que farão com que os alunos fortifiquem seus vínculos, resultando em mais interesse em continuar juntos, em contribuir com o grupo, em encantar os colegas com suas contribuições. Além disso, é a partir da relação aluno-aluno que o inusitado pode acontecer. A expressão das subjetividades dos alunos será favorecida quando o professor montar cenários para atuação de seus alunos, deixando um sentido de indeterminância "no ar", o qual, sutilmente, convida para a co-autoria. O processo passará, então, a ser coordenado pelos alunos, com toda a beleza e com todas as surpresas que aparecem quando se permite que as subjetividades e suas diversidades venham à tona.

Outra característica da EAD é a grande quantidade de produção dos alunos, registrada, em grande parte, na forma escrita. Em EAD, os alunos escrevem muito, 
produzem muito. Talvez, a grande produção escrita por parte dos alunos constitua-se em outro diferencial positivo da EAD. A escrita exige uma reorganização maior do pensamento que a fala. O fato de ficar tudo publicado nos AVA, tornando-se uma informação de caráter coletivo, costuma aumentar o senso de responsabilidade no aluno. Além disso, o fato de as produções serem de sua própria autoria e, assim, representarem a expressão de si próprio, favorece que o aluno aumente o prazer, o entusiasmo e autoestima.

Assim sendo, essas características da EAD exigem do professor, além do conhecimento dos recursos informáticos e de suas características e potencialidades, um outro saber específico desta modalidade de educação que é a gestão desses recursos informáticos e do tempo que o professor dispõe para utilizá-los.

\section{Os saberes pedagógicos e comunicacionais em EAD}

Da mesma forma, a ação do professor na modalidade EAD poderá ser favorecida quando ele fizer uso de potencialidades dos recursos existentes nos AVA como, por exemplo, de uma lógica comunicacional aberta e flexível. A capacidade de utilizá-la de forma positiva para todo o grupo, a compreensão e uso de interatividade, a capacidade de pensamento complexo e de uso das características das Comunidades Virtuais de Aprendizagem (CVA) que se formam nos AVAs podem constituir-se em elementos que favorecem ações docentes em EAD na perspectiva do conhecimento solidariedade.

Outro aspecto específico da modalidade EAD refere-se à capacidade de concretude e resiliência das informações. Isto é, todos os conteúdos, inclusive o conteúdo das trocas, ficam gravados no ambiente. Os alunos podem se voltar para eles tantas vezes quantas necessitarem, podem transformá-los mentalmente ou em outro espaço digital ou não, que, mesmo assim, esses conteúdos sempre voltarão à sua forma original. Como a aprendizagem ocorre por aproximações e como cada vez que o sujeito se volta para o objeto de aprendizagem pode apreender caracteres que, anteriormente, não havia aprendido, a concretude e a resiliência das informações em um ambiente EAD constituem-se em especifidades da EAD que podem significar vantagens para o aluno. As capacidades de abstração e da memória ficam mais liberadas e, não havendo essa dependência delas, garante-se a exatidão das informações, sem os "ajeitamentos" que a mente opera.

No que diz respeito à lógica de comunicação, os recursos existentes na modalidade EAD dão ao professor a possibilidade de deixar de lado a lógica linear de comunicação presente na maioria das salas de aula, onde enquanto alguém fala, os outros devem escutar. É possível uma comunicação de muitos para muitos, a partir de qualquer lugar e a qualquer hora. Isto é, de forma muito diferente da aula presencial, na medida em que ocorre o pensamento, ele pode ser expresso, muitas vezes de forma espontânea, sem as travas da auto-censura. Alunos introspectivos costumam sentir-se mais à vontade para manifestar-se, fazendo colocações que dificilmente fariam de forma presencial.

Porém, é importante reforçar que, embora os recursos em EAD coloquem à disposição do professor a possibilidade dessa nova lógica comunicacional que possibilita à interatividade, nada mudará se o professor não tiver disposição para mais abertura, mais trocas, mais intervenções, mais construções conjuntas. Além disso, a qualidade das trocas é mais importante que o conteúdo que elas contêm. Relações respeitosas e interessadas têm forte influência na construção de personalidades éticas.

O pensamento linear, característico da lógica de comunicação tradicional, prejudica a interatividade. É o pensamento complexo, aberto, flexível que permite ao professor agir de 
acordo com esta nova lógica de comunicação. É ele, também, a porta que se abre para o conhecimento-solidariedade.

O uso dos recursos dos AVA permite ao professor incentivar a criação de verdadeiras Comunidades Virtuais de Aprendizagem (CVA), nas quais existe uma identificação em comum, um sentimento de pertença, além de propósitos e conhecimentos em comum. Fazer parte de um grupo com o qual é identificado é uma das características dos seres humanos, bem como unir-se para atingir objetivos comuns. Palloff e Pratt (2002) apresentam seis elementos que contribuem para o sucesso de uma CVA, são eles: honestidade, correspondência, pertinência, respeito, franqueza e autonomia.

A inspiração no paradigma da solidariedade está relacionada com a complexidade. O pensamento linear, cartesiano não é suficiente para dar conta da complexidade do mundo e de cada ser humano, de forma especial. O pensamento complexo consegue atuar como um ligador que supera as dicotomias e articula saberes vistos como separados.

É com este tipo de pensamento que o professor em EAD se sentirá com possibilidade de atender sua proposta de inspiração no paradigma da solidariedade. Além disso, o pensamento de Santos (2002) em relação à atitude coerente com o paradigma da solidariedade inclui o que ele chama de uma nova subjetividade: a subjetividade da fronteira. Considerando que estamos vivendo novos tempos e que, para caminhar na perspectiva do conhecimento-solidariedade teremos que trilhar caminhos totalmente desconhecidos, porque fogem aos padrões anteriores fornecidos pelo paradigma da ciência moderna, o autor diz que o sentimento ideal é semelhante àquele que os pioneiros tiveram ao desbravar terras desconhecidas, ao buscar as "terras de ninguém".

Agir na fronteira, sem mapas referenciais, exige uma nova forma de sociabilidade onde coexistem "hierarquias fracas, pluralidade de poderes e ordens jurídicas, fluidez das relações sociais, promiscuidade entre estranhos e íntimos, misturas de heranças e invenções" (Santos, 2002, p.347). Essa forma de viver combina participação comunitária e autoria, eliminando, assim, a distinção entre sujeito e objeto. É, também, uma forma de viver onde praticamente não existe um poder central, uma única referência a ser seguida. Assim sendo, para poder sobreviver, a autonomia e a criatividade são exigidas, assim como o sentimento de comunidade a solidariedade. Para Santos "nenhuma transformação paradigmática será possível sem a transformação paradigmática da subjetividade" (2002, p.333). Essa subjetividade de fronteira de que fala Santos (2002) é a subjetividade que favorece as ações em EAD na perspectiva do conhecimento-solidariedade.

Assim sendo, ao recuperar a importância do reconhecimento das subjetividades, os docentes estarão caminhando na direção de Santos (2002) quando menciona que todo conhecimento é auto-conhecimento. A ação docente na perspectiva do conhecimentosolidariedade reconhece também, que as intersubjetividades dependem da concepção do próximo numa teia de reciprocidade, isto é, esta nova subjetividade é muito mais dependente da reciprocidade, do que da identidade, enfatizando a importância dos saberes éticos.

\section{Considerações Finais}

A seguir, o quadro 2 procura demonstrar, de forma resumida, os saberes docentes em EAD na perspectiva do conhecimento-solidariedade. 
Quadro 2: Resumo das dimensões dos saberes docentes em EAD na perspectiva do conhecimento solidariedade

\begin{tabular}{|c|c|}
\hline Dimensão & Saberes Docentes \\
\hline \multirow[t]{7}{*}{ Pedagógica } & Paradigma Emergente \\
\hline & Concepção de conhecimento construtivista \\
\hline & Pedagogia Relacional \\
\hline & Pensamento divergente, complexo, flexível \\
\hline & $\begin{array}{l}\text { Saber fazer uso da possibilidade de grande produçao escrita e de suas } \\
\text { características de exigência de maior organizaçao de pensamento, aumento de } \\
\text { auto-estima, responsabilidade, prazer e entusiasmo. }\end{array}$ \\
\hline & $\begin{array}{l}\text { Saber usar a capacidade de concretude e resiliência das informaçoes para obtençao } \\
\text { de maior reciprocidade nas relaçoes e reversilidade de pensamento. }\end{array}$ \\
\hline & $\begin{array}{l}\text { Saber usar a possibilidade de criaçao de CVA e de cenários e estratégias para } \\
\text { disponibilização e tratamento dos conteúdos. }\end{array}$ \\
\hline \multirow[t]{2}{*}{ Comunicacional } & Lógica de comunicação aberta, complexa, flexível \\
\hline & $\begin{array}{l}\text { Interatividade, no sentido de disposiçao interna para grande quantidade de trocas e } \\
\text { no sentido de deixar uma ïndeterminância no ar" que funcione como uma abertura } \\
\text { para a co-autoria, com o objetivo de favorecer a reciprocidade, a tomada de } \\
\text { consciências das próprias ações, objetividade e a criatividade. }\end{array}$ \\
\hline Técnica & Familiaridade com o uso de recursos informáticos incluindo TICs e AVAs. \\
\hline \multirow[t]{2}{*}{ Gestão } & Gestão do tempo \\
\hline & Gestão dos recursos informáticos-comunicacionais \\
\hline \multirow[t]{3}{*}{ Ética } & Saber ser solidário \\
\hline & Querer ser solidário \\
\hline & Poder ser solidário \\
\hline
\end{tabular}

A partir da reflexão realizada ao longo do texto e com o auxílio da sistematização apresentada nos QUADROS 1 e 2 estamos implementando uma investigação sobre como são percebidas ações pedagógicas na perspectiva do conhecimento-solidariedade, junto a professores e alunos de seis turmas oferecidas, no primeiro semestre de 2007, na modalidade EAD na UCPel, buscando-se responder questões como:

- Quais condições pedagógicas e técnicas favorecem o desenvolvimento do conhecimento-solidariedade na modalidade de EAD?

- Que saberes pedagógicos são mobilizados para desenvolver uma experiência em EAD na perspectiva do conhecimento-solidariedade?

- Que valores podem ser destacados nas ações pedagógicas assentadas no conhecimento-solidariedade?

Estamos buscando, de forma especial, nas trocas professor-aluno e aluno-aluno, indicativos do desenvolvimento do conhecimento-solidariedade. A produção dos sujeitos, armazenada nos recursos (fórum, portfólio individual, portfólio grupal, diário de bordo...) existentes no AVA utilizado pela UCPel - o TelEduc -, é a principal fonte para análise de dados. Procurar-se-á mapear a produção separando-a quanto à existência ou ausência de indicadores relacionados a ações pedagógicas na perspectiva do conhecimento-solidariedade. Outros procedimentos, como entrevistas, grupos de discussão, entre outros, poderão ser utilizados à medida que o processo de investigação for sendo gerado.

\section{Referências}




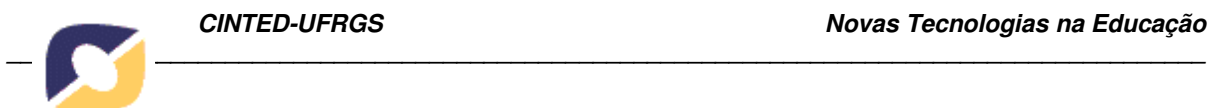

BECKER. Fernando Educação e construção de conhecimento. Porto Alegre: Artmed Editora, 2001

Tempo de aprendizagem, tempo de desenvolvimento, tempo de gênese. In: MOLL, Jaqueline et al. Ciclos na Escola, tempos da vida. Criando possibilidades. Porto Alegre: Artmed, 2004.

FREIRE, Paulo. Pedagogia da autonomia. Rio de Janeiro: Editora Paz e Terra, 1997.

LA TAILLE, Yves de. Vergonha, a ferida moral. Petrópolis, RJ: Vozes, 2002.

. Moral e ética: dimensões intelectuais e afetivas. Porto Alegre: Artmed, 2006.

MARQUES, Tânia. Do egocentrismo à descentração: a docência no ensino superior. Tese de Doutorado. Programa de Pós-Graduação em Educação, UFRGS, 2005.

MORAES, Maria Cândida. O paradigma educacional emergente. Tese de Doutorado em Educação - PUC/SP, 1996.

TORRE, Saturnino. Sentipensar: fundamentos e estratégias para reencantar a educação. Petrópolis, RJ: Vozes, 2004.

PALLOF, Rena M; PRATT, Keith. Construindo Comunidades de Aprendizagem no Ciberespaço: estratégias eficientes para salas de aula on-line. Porto Alegre: Editora. Artmed, 2002.

PIAGET Jean. Abstração relexionante: relações lógico-aritméticas e ordem das relações espaciais. Porto Alegre: Artes Médicas, 1995.

SANTOS, Boaventura de Souza. Um discurso sobre as Ciências. Porto: Afrontamento, 1987.

A crítica da razão indolente: contra o desperdício da experiência. São Paulo: Cortez, 2002. 